\title{
MASTER
}

\section{Scale-Model Study of the Seismic Response of a Nuclear Reactor Core}

西

$\frac{7}{\infty}$

$\frac{1}{d}$

$\frac{2}{5}$

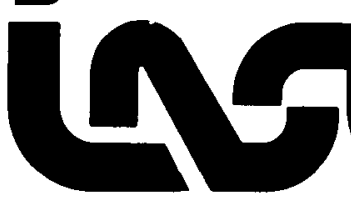




\section{DISCLAIMER}

This report was prepared as an account of work sponsored by an agency of the United States Government. Neither the United States Government nor any agency Thereof, nor any of their employees, makes any warranty, express or implied, or assumes any legal liability or responsibility for the accuracy, completeness, or usefulness of any information, apparatus, product, or process disclosed, or represents that its use would not infringe privately owned rights. Reference herein to any specific commercial product, process, or service by trade name, trademark, manufacturer, or otherwise does not necessarily constitute or imply its endorsement, recommendation, or favoring by the United States Government or any agency thereof. The views and opinions of authors expressed herein do not necessarily state or reflect those of the United States Government or any agency thereof. 


\section{DISCLAIMER}

Portions of this document may be illegible in electronic image products. Images are produced from the best available original document. 
An Affirmative Action/Equal Opportunity Employer

NOT ICF

This report was prepured as an account of work sponsored by an atency of the Unitod States Government. Nest her the United Sutes Government not iny enency thereor, ot any of their employees, makes any werranty, expressed or umpted, Unhed Sutes Government not any wency thereof, of any of theer employees, makes sny werranty, expressed or impled,

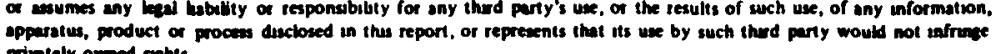




\section{Scale-Model Study of the Seismic Response of a Nuclear Reactor Core}

Richard C. Dove W. E. Dunwoody

R. L. Rhorer

Manuscrıpt submitted: April 1981

Date published: May 1981
Prepared for

Division of Reactor Safety Research Office of Nuclear Regulatory Research US Nuclear Regulatory Commission

Washıngton, DC 20555

NRC FIN No. A7014

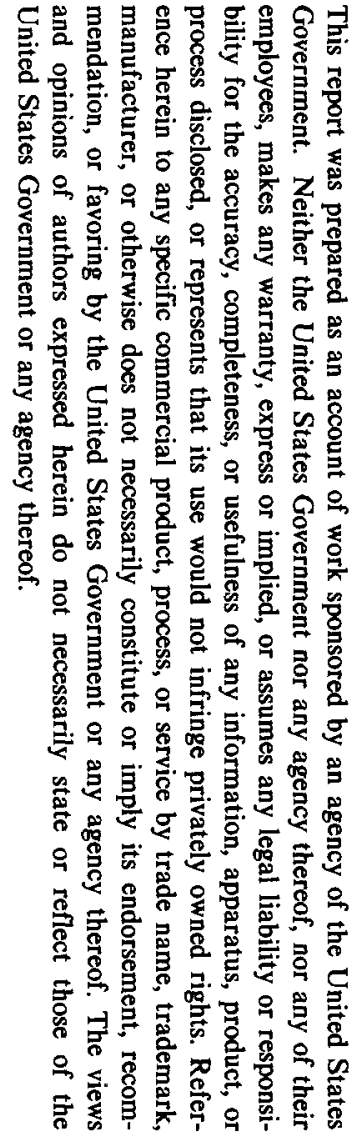




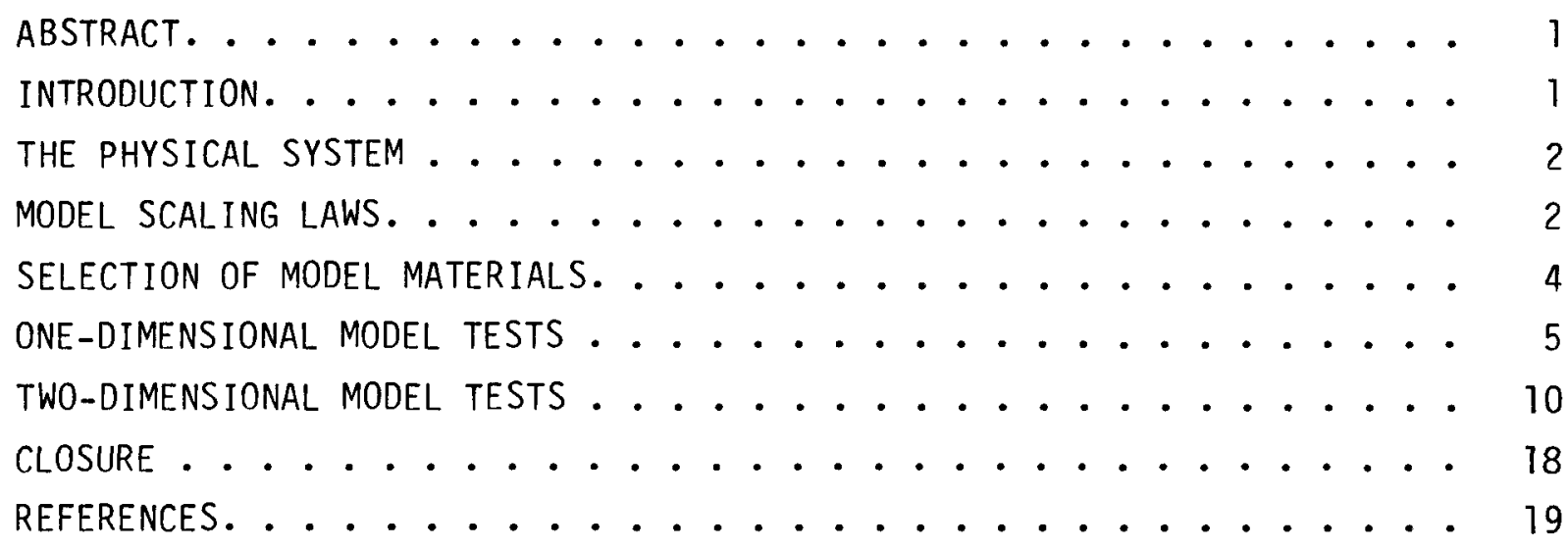

FIGURES

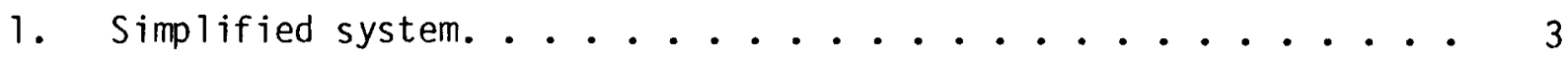

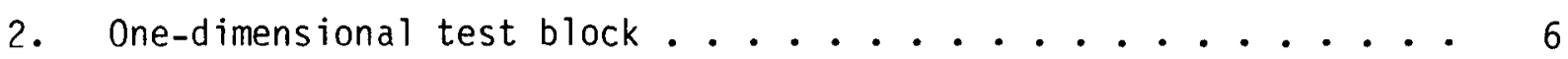

3. One-dimensional system mounted on the seismic simulator. . . . 7

4. Two-dimensional assembly fixture .............. 11

5. Two-dimensional block instrumentation. ......... 11

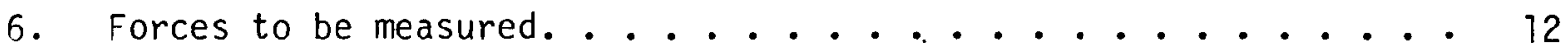

7. Two-dimensional core block dimensions. .......... 13

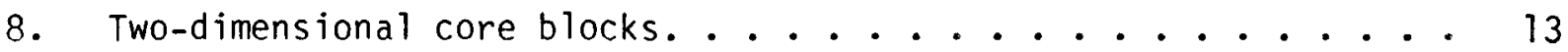

9. Model mounted and ready for testing. ............ 14

10. Block clearance identification ................. 14

TABLES

I. ONE-DIMENSIONAL TEST BlOCK DIMENSIONS. . . . . . . . . 7

II. MAXIMUM STRAIN PRODUCED IN FOUR-BLOCK SYSTEMS DURING

SIMULATED EARTHQUAKE TESTS .............. 8

III. MAXIMUM STRAIN PRODUCED IN FRICTION CORRECTED FOUR-BLOCK SYSTEMS SIMULATED EARTHQUAKE TESTS ............. 10

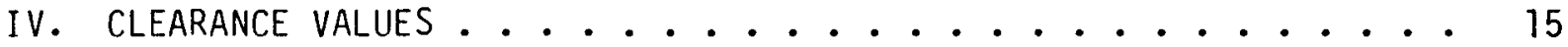

V. SHEAR PIN PEAK FORCES (Newtons) ................ 16

VI. SIDE WALL CONTACT PEAK FORCES (Newtons).......... 16 
SCALE-MODEL STUDY OF THE SEISMIC RESPONSE OF A NUCLEAR REACTOR CORE

by

\author{
Richard C. Dove, W. E. Dunwoody, \\ and R. L. Rhorer
}

\begin{abstract}
The use of scale models to study the dynamics of a system of graphite core blocks used in certain nuclear reactor designs is described. Scaling laws, material selection, model instrumentation to measure collision forces, and the response of several models to simulated seismic excitation are covered. The effects of

(1) Coulomb friction between the blocks, and (2) the clearance gaps between the blocks on the system response to seismic excitation are emphasized.
\end{abstract}

\title{
INTRODUCTION
}

The use of a large number of graphite elements to form the core of a nuclear reactor is not new. However, a recent core design for a large gas-cooled reactor contains a very large number of graphite blocks, and, in accord with present practice, the seismic response of this core must be accurately predicted. Such a system of blocks does not constitute a structure in the usual sense, and, hence, the theory and experimental data available for the prediction of seismic response cannot be directly applied.

Nuclear reactor cores that consist of graphite blocks of various shapes have been described by several authors. The physical system of interest in this investigation was one described by Neylan and Gorholt. ${ }^{1}$ This core 
system, for use in large high temperature gas-cooled reactors (HTGRs), was developed by the General Atomic Company of San Diego, California. The core consists of a large number of hexagonally shaped graphite blocks with a great number of degrees-of-freedom and with complicated boundary and support conditions.

\section{THE PHYSICAL SYSTEM}

A model of this system should consist of a three-dimensional array of elements that can be excited by three independent axial motions representing three earthquake components, and for which the six components of motion and all forces can be measured on each element. Such a complex model and the associated test facility were judged to be beyond the resources of the present research. Furthermore, it was believed that the important structured features of this actual reactor core could be investigated using a greatly simplified system.

Figure 1 illustrates the simplified two-dimensional core array that was used as a basis for the models designed and tested in this research. The important features that have been preserved, and which were to be investigated in this model study, are the coulomb friction between blocks in a column, the clearance gaps between adjacent columns, and the clearance gaps between the dowel pins and dowel sockets that connect adjacent vertical blocks.

To date, models of this simplified structure have only been tested using horizontal excitation; however, they can be tested using vertical and/or simultaneous vertical and horizontal excitation if desired.

\section{MODEL SCALING LAWS}

The applicable scaling laws can be developed in the usual way from similitude theory; this has been reported elsewhere and will not be repeated here. $^{2}$ The scaling laws can be stated as follows:

Case A - Gravitation effects (body forces) are correctly scaled Length Scale $=\mathrm{N}_{\mathrm{L}}$ where

$$
N_{L}=N_{E} / N_{\rho}
$$

$$
N_{L}=\ell_{\text {prototype }} / \ell_{\text {mode }} 1
$$




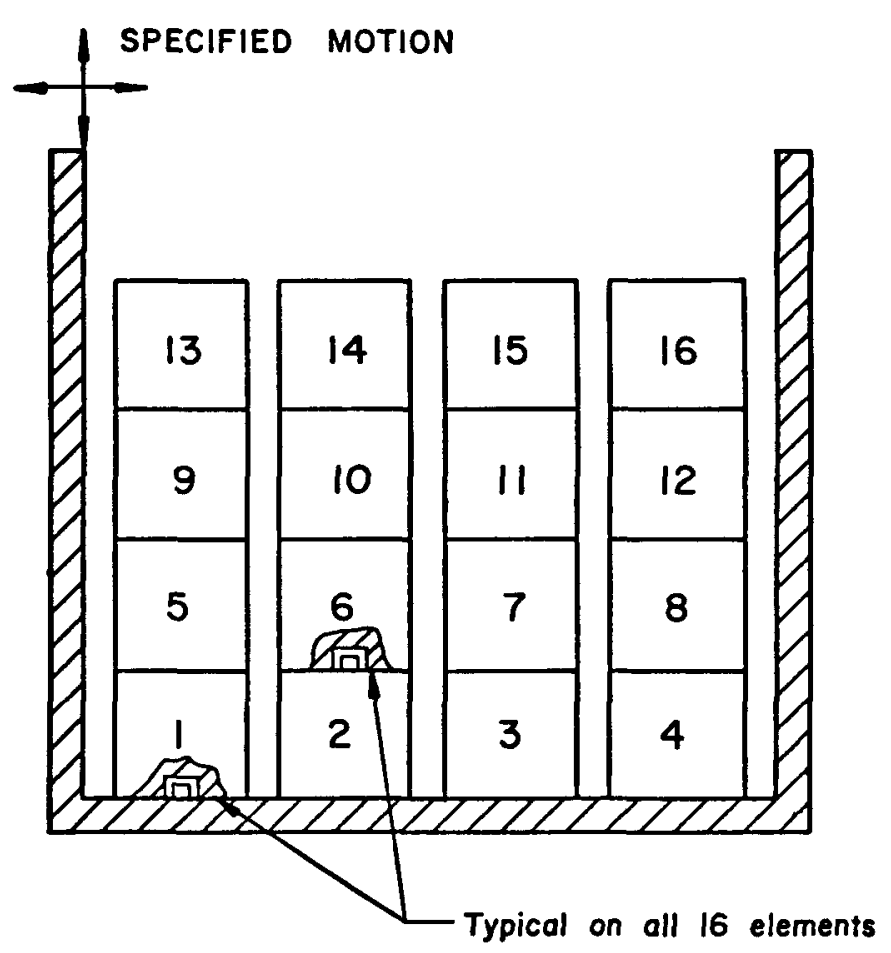

Fig. 1. Simplified system.

$N_{E}=$ modulus scale. In the linear elastic region this would be the modulus of elasticity scale $E_{\text {prototype }} / E_{\text {model }}$. In the more general case, this scale implies complete similarity between the stress-strain diagrams of the prototype and model materials; density scale, $\rho_{\text {prototype }} / \rho_{\text {model }}$.

$$
\begin{gathered}
\frac{\text { Force Scale }}{N_{F}=N_{E} N_{L}^{2}} \\
\text { Time Scale }=N_{t} \\
N_{t}=\sqrt{N_{L}}
\end{gathered}
$$

Acceleration Scale $=N_{x}$ $N_{x}=1$

Case B - The same material is used in both the model and prototype so that $N_{E}=1$ and $N_{\rho}=1$. Then, $N_{L}$, the length scale can be assigned any desired value; it is independent of material properties. 


$$
\begin{aligned}
& N_{F}=N_{L}^{2}, \\
& N_{t}=N_{L}, \\
& N_{x}=1 / N_{L},
\end{aligned}
$$

In this case (same material used in the model and prototype) the gravitational forces will all be distorted, relative to other forces such as contact forces and inertia forces. As a result, all coulomb friction forces will also be distorted because they are directly related, through the coefficient of friction, to the normal forces produced by gravity. Specificaliy, if the model is constructed from the same material as is the prototype (graphite in this case), the friction forces in the model will be too small by a factor equal to the length scale $N_{L}$.

For the purposes of this research, both types of models were constructed and tested, that is, one model based on the scaling laws given in case $A$ above, and one model based on the scaling laws given in Case $B$ above.

\section{SELECTION OF MODEL MATERIALS}

When a model is to be designed to satisfy the design condition $N_{L}=$ $\mathrm{N}_{E} / \mathrm{N}_{\rho}$, the first problem is the selection of the model material. Because a reactor core is large and massive, practicability dictates that seismic testing be performed on a model having a length scale $\left(N_{L}\right)$ greater than unity, that is, a model smaller than the prototype. Using handbook values for density $(\rho)$ and modulus of elasticity $(E)$, we can readily eliminate materials that would not be suitable as models for reactor-grade graphite. For example, most metals would result in a length scale of less than unity, that is, the model would be larger than the graphite prototype. On the other hand, several plastics have density and modulus of elasticity values such that length scales from 1 to 6 should be possible.

Computation of a possible value of $\mathrm{N}_{L}$ using handbook values for material properties ( $\rho$ and $E$ ) is only a first step. Neither the prototype graphite nor many of the potential model materials can be characterized by a single, constant value of modulus-of-elasticity (E), especially at the loading rates associated with block collision. As a result, the final selection of model material and the actual length scale $\left(N_{L}\right)$ to be used must be determined by experiment. Preferably, this experiment should involve loading rates and 
strain levels that will exist in the final model experiments. In this research, these model-material-selection experiments involved impact tests carried out on small cubes of both the plastic candidate materials and the prototype graphite. A detailed discussion of these preliminary experiments can be found in Ref. 2 .

As a result of these experiments, plexiglas was selected to model type A-378 graphite in some preliminary one-dimensional tests, and Lexan was selected to model type HLM graphite in the two-dimensional tests. For the Plexiglas/A-378 combination, $N_{L}=1.63$; and for the Lexan/HLM combination, $\mathrm{N}_{\mathrm{L}}=3.45$.

ONE-DIMENSIONAL MODEL TESTS

The principal objective of the 1-D model test program was to determine the feasibility of using a plastic model to predict the response of a system of graphite blocks, which was excited to produce interblock collisions by a base displacement forcing function. This objective was pursued because previously conducted scaling law studies and analytical modeling ${ }^{3}$ had shown that if the same material (graphite) were used to construct both the model and the prototype, the model prediction would be in error due to distortion of the friction effect.

The 1-D model test program resulted in the construction and test of three distinct physical systems:

1. a system of six large graphite $(A-378)$ blocks considered to be the prototype system;

2. a system of six smaller graphite (A-378) blocks considered to be a model of the larger system; and

3. a system of six smaller plastic (Plexiglas) blocks also considered to be a model of the larger system.

The block shape and dimensions for all three systems are given in Fig. 2 and Table I. Figure 3 shows a system mounted on the seismic simulator at the White Sands Missile Range (WSMR). The two end blocks are clamped to the aluminum base plate, which, in turn, is bolted to the seismic simulator table. The four center blocks are free to slide on the base plate in the direction of the applied table displacement. Transverse motion is limited by side rails. Graphite dust is sprinkled between the blocks and the aluminum 
base plate so that all the systems, including the Plexiglas model, have the same coefficient of sliding friction.*

All three one-dimensional systems (the graphite prototype, the graphite model, and the plastic model) were subjected to a series of simulated earthquake tests.

The four-block prototype system was subjected to five simulated earthquake tests. The exciting function (the simulated earthquake) was the same for each test within the limits of the ability of the servohydraulic system to reproduce the control signal. The initial clearance gap between blocks and the starting position of the blocks was identical for each test within the limits of setup error. Table II shows the maximum strains produced in the prototype system for each of the five tests, together with the average value.

The four-block plastic model system was also subjected to five earthquake tests, which were as nearly identical as possible. For these model tests, the acceleration-time history used as the exciting function was properly time scaled using the scaling laws previously discussed, that is, $N_{t}=\sqrt{N_{L}}$ and $N_{\ddot{x}}=1$. The maximum strains produced in the model system for each of the

*For a detailed discussion of preliminary tests to determine the coefficient of friction and as final scaling checks see Ref. 2 .

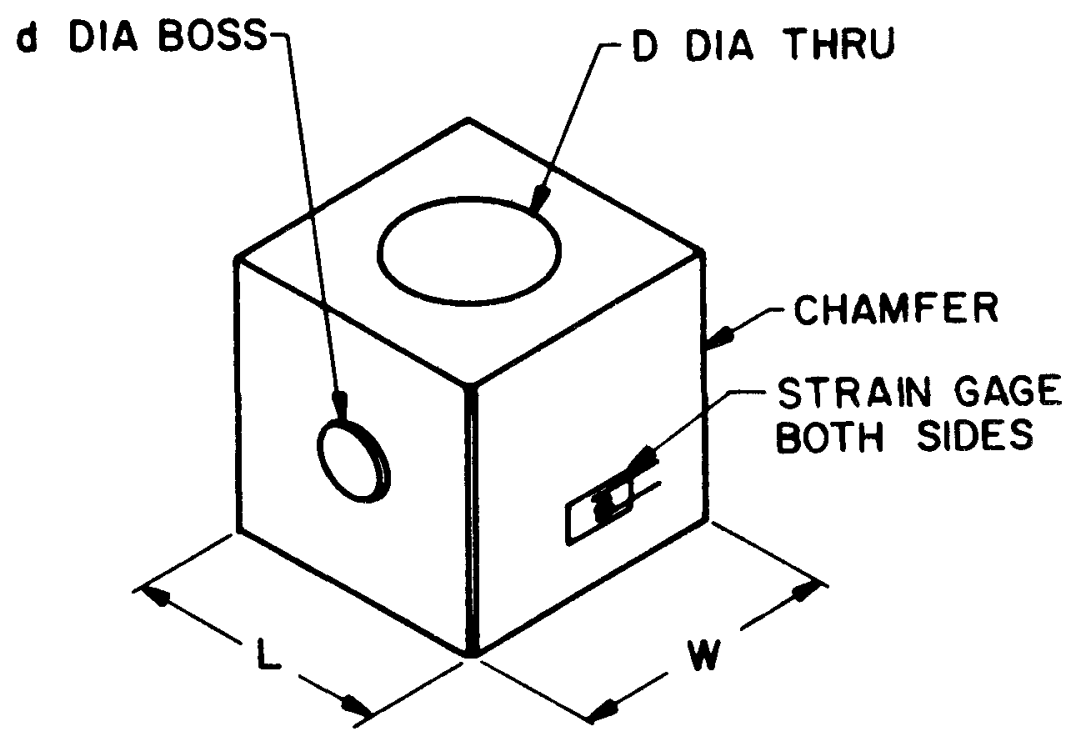

Fig. 2. One-dimensional test block. 
TABLE I

ONE-DIMENSIONAL TEST-BLOCK DIMENSIONS

Dimension

(See Fig. 2)

L

W

D

d

Gage length

Prototype System
A-378 Graphite
$(\mathrm{mm})$

76.20

73.91

47.63

23.82

3.18
Model Systems One of A-378 Graphite one of Plexiglas (mm)

46.73

45.34

29.22

14.61

1.59

Note: Model dimensions are equal to prototype dimensions divided by the length scale $\left(N_{L}=1.63\right)$ except for the gage length.

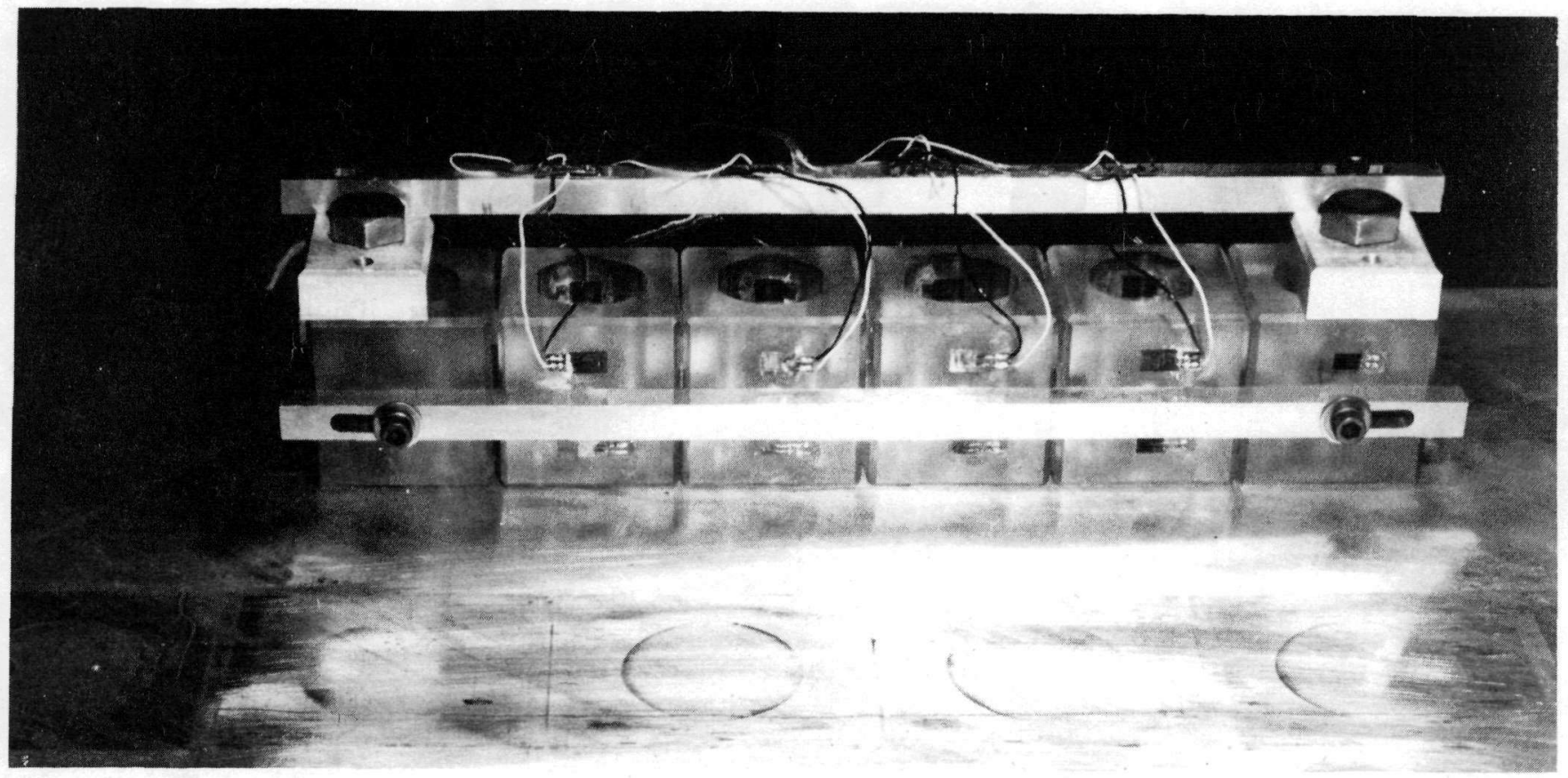

Fig. 3. One-dimensional system mounted on the seismic simulator. 
five tests, together with the average value, are also shown in Table II. These data indicate that this model predicts amplitude of response (as measured by strain produced) reasonably well, but that there is more variation in results for "identical" model tests than there is for "identical" prototype tests. We believe the reason for this is the fact that static frictional effects are more difficult to control in the model system than in the prototype system.

The third series of tests involved the testing of the graphite model. This model was known, from theoretical considerations, to be a "distorted" model, in that all frictional forces are improperly scaled (too small) as compared with inertial and contact forces. The question to be investigated in this study was: "What is the effect on system response of this distortion of frictional forces?" As a result of analytical studies, ${ }^{4,5}$ we expected use of a distorted model to result in a prediction of strains (or accelerations) larger than would actually be produced in a prototype. However, with simulated earthquake excitation, the actual magnitude of the effect of the distortion had not been determined from analysis.

TABLE II

MAXIMUM STRAIN PRODUCED IN FOUR-BLOCK SYSTEMS DURING SIMULATED EARTHQUAKE TESTS

\begin{tabular}{|c|c|c|c|}
\hline Test & $\begin{array}{c}\text { Max Strain in } \\
\text { Prototype } \\
\times 10^{6}\end{array}$ & $\begin{array}{l}\text { Max Strain in } \\
\text { Plastic Model } \\
\times 10^{6}\end{array}$ & $\begin{array}{l}\text { Max Strain in } \\
\text { Graphite Mode } \\
\times 10^{6}\end{array}$ \\
\hline 1 & 212 & 212 & 265 \\
\hline 2 & 191 & 187 & 223 \\
\hline 3 & 191 & 170 & 254 \\
\hline 4 & 201 & 254 & 244 \\
\hline 5 & 223 & 191 & 254 \\
\hline erage of 5 tests & 204 & 201 & 248 \\
\hline $\begin{array}{l}\text { viation from av } \\
\text { ror in prediction } \\
\text { of average maximum }\end{array}$ & $-6.4 \%$ to $+9.3 \%$ & $\begin{array}{c}-15.4 \% \text { to }+25.4 \% \\
-1.4 \%\end{array}$ & $-10 \%$ to $+6.8 \%$ \\
\hline
\end{tabular}


The graphite model was subjected to five identical earthquake tests. The acceleration-time history used as the exciting function was also properly scaled for acceleration and time, for this case $N_{t}=N_{L}$ and $N_{\ddot{x}}=1 / N_{L}$. The maximum strains produced in the distorted model system for each of the five tests, together with the average value, are shown in Table II. The measured strain and, hence, the predicted strain, since strain is scaled by a factor of unity, is larger than the strain measured in the prototype test. This finding confirms the distorted model theory previously discussed.

To further investigate the importance of coulomb damping (friction), a second series of one-dimensional model tests was run. In these tests, the graphite prototype system was subjected to five identical simulated earthquake events. Peak strains produced by block impacts were recorded and are given in Table III. The graphite model was also subjected to five identical earthquake events that were appropriately scaled relative to the prototype pulse; these results of these tests are also shown in Table III. The graphite model system was then disassembled, and friction disks* were bonded to the base of each model block. Following this modification to increase the static $\left(\mu_{s}\right)$ and kinetic $\left(\mu_{k}\right)$ coefficients of friction of the model, the model was again subjected to the same earthquake events to which it had previously been subjected. The results of these tests are also shown in Table III.

These tests, which used a somewhat different earthquake signal than had been used in previous tests, reaffirm the findings previously reported, that is, the graphite model is distorted with frictional effects too small, and, as a result, it predicts strains that are too large. In addition, these tests show that for this one-dimensional system, it is possible to "correct" the distorted model by adjustment of the coefficient of friction. This method of compensating for "distortion" has been discussed in a previous report. 5

Because the collision of the core blocks produced by seismic excitation is a complex dynamics problem, this verification of scale model theory, using 1-D systems excited by simulated earthquakes, was considered to be an important step in the development of the 2-D core mode1. In addition to the scaling law verification, the $1-D$ scale model program gave valuable information in other areas such as:

* 1/4-in.-diam disks of 120 -grit SiC. This produced a static coefficient $\left(\mu_{s}\right)$ of 0.61 , and a kinetic coefficient $\left(\mu_{k}\right)$ of 0.39 . 
TABLE III

MAXIMUM STRAIN PRODUCED IN FRICTION-CORRECTED FOUR-BLOCK SYSTEMS DUR ING SIMULATED EARTHQUAKE TESTS

\section{Test}

1
2
3
4
5

Average of 5 tests

Deviation from av (\%)

Error in Prediction of av $\max (\%)$

$\begin{array}{ccc}\begin{array}{c}\text { Max Strain } \\ \begin{array}{c}\text { Prototype } \\ \times 10^{6}\end{array}\end{array} & \begin{array}{c}\text { Max Strain in } \\ \text { Graphite Mode } \\ \times 10^{6}\end{array} & \begin{array}{c}\text { Max Strain in } \\ \text { Friction- } \\ \text { Corrected } \\ \text { Graphite Model } \\ \times 10^{6}\end{array} \\ \begin{array}{ccc}150 \\ 173\end{array} & 231 & 208 \\ 173 & 266 & 162 \\ 185 & 266 & 162 \\ 185 & 266 & 162 \\ 173 & 257 & 164 \\ -13+6 & -10+4 & -22+27\end{array}$

1. model material selection,

2. model instrumentation techniques, and

3. effective use and limitations of the earthquake simulator at the WSMR.

TWO-DIMENSIONAL MODEL TESTS

The 2-D core block model was designed to represent a 4 by 6 block array as shown in Fig. 4. The two end columns were fixed to the frame, hence this model simulates a 4 by 4 array of "loose" core blocks that impact on reflector blocks (the 8 blocks in the two end columns), which are rigidly attached to a rigid frame. A simulated seismic motion is applied to the base of this frame. The four blocks in each column are loosely connected to each other and to the frame base by means of a shear pin and socket. A shear pin that protrudes from the lower surface of each block fits into a socket bored into the upper surface of the supporting block (or base plate). Figure 5 shows a block in cross section and indicates how the side wall contact surfaces and the shear pins are instrumented to measure the contact forces that will be developed between blocks 


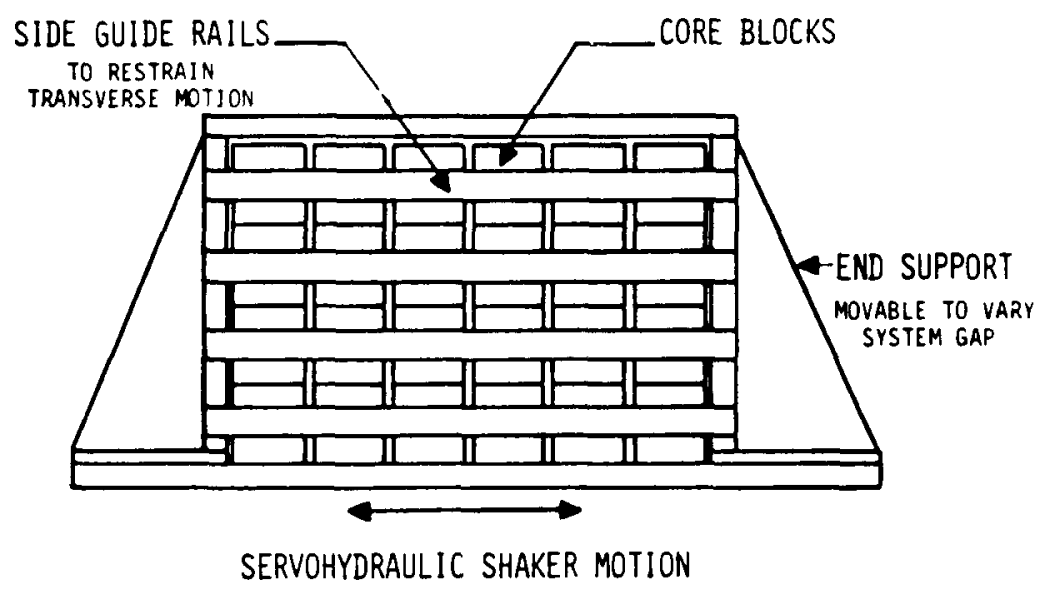

Fig. 4. Two-dimensional assembly fixture.

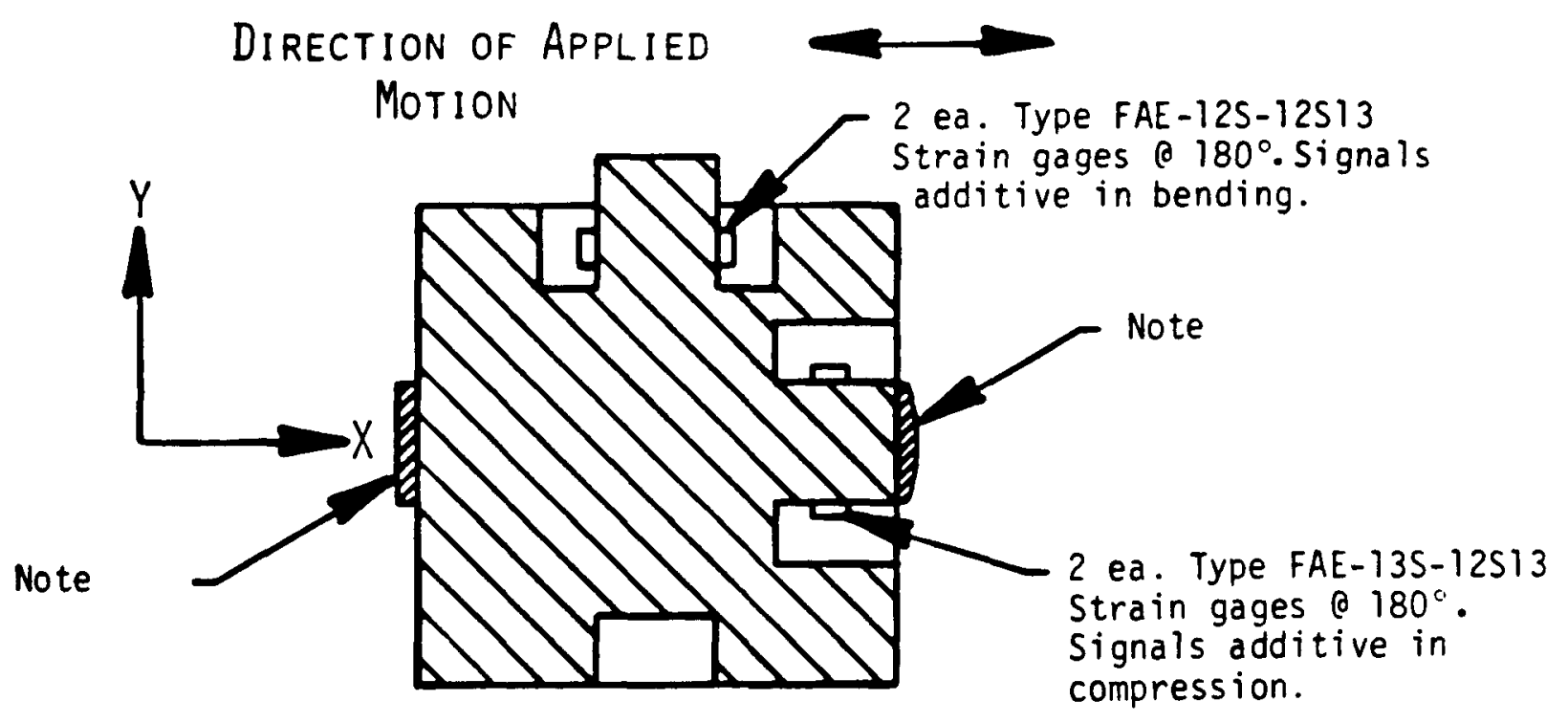

Note : Impact pieces bonded to block to prevent progressive degradation of impact point. Impact piece is steel on HLM graphite blocks and magnesium on the polycarbonate blocks.

Fig. 5. Two-dimensional block instrumentation. 
in a given horizontal row and the shear forces that will be developed between the blocks in a given column. Figure 6 identifies the forces that are to be measured.

For this 2-D core-block model study an HLM graphite was selected as the prototype material, and a polycarbonate plastic (Lexan) was selected as the true model material. Preliminary material property tests indicate that the appropriate length scale for this combination of materials was 3.45. Model block dimensions are shown in Fig. 7. Figure 8 shows the three types of blocks constructed (two sizes of graphite and one size of Lexan).

A full array ( 4 by 6 ) of polycarbonate blocks was instrumented, calibrated, ${ }^{6}$ and assembled in preparation for testing at the WSMR. Figure 9 shows the model mounted and ready for testing on the servohydraulic earthquake simulator at WSMR. The 2-D model was used to investigate the effects of the two types of clearances involved in this type of reactor core:

1. the clearance between block sidewalls $\left(\mathrm{C}_{S W}\right)$, and

2. the radial clearance between shear pins and sockets $\left(C_{R}\right)$.

It was our belief that variation in these two parameters might have a significant effect on the core structure response to seismic excitation, and furthermore, that these effects are the most difficult to predict using analytical tools only.

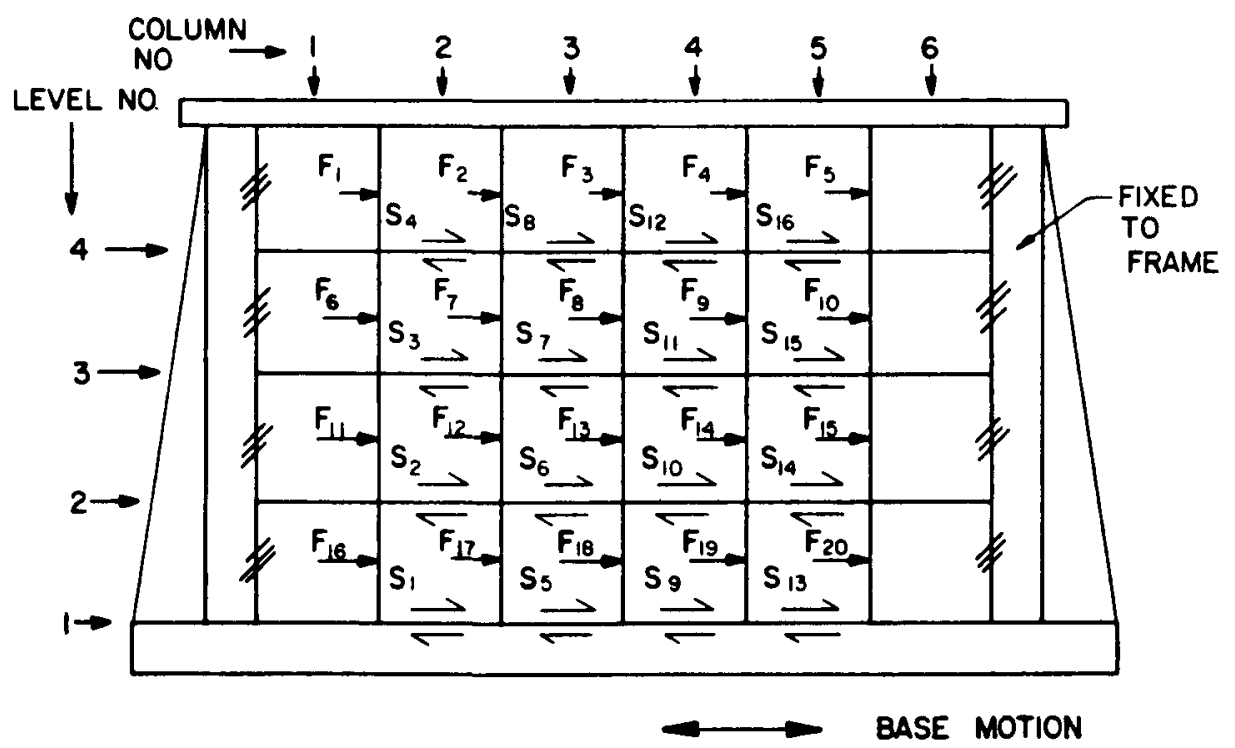

Fig. 6. Forces to be measured. 


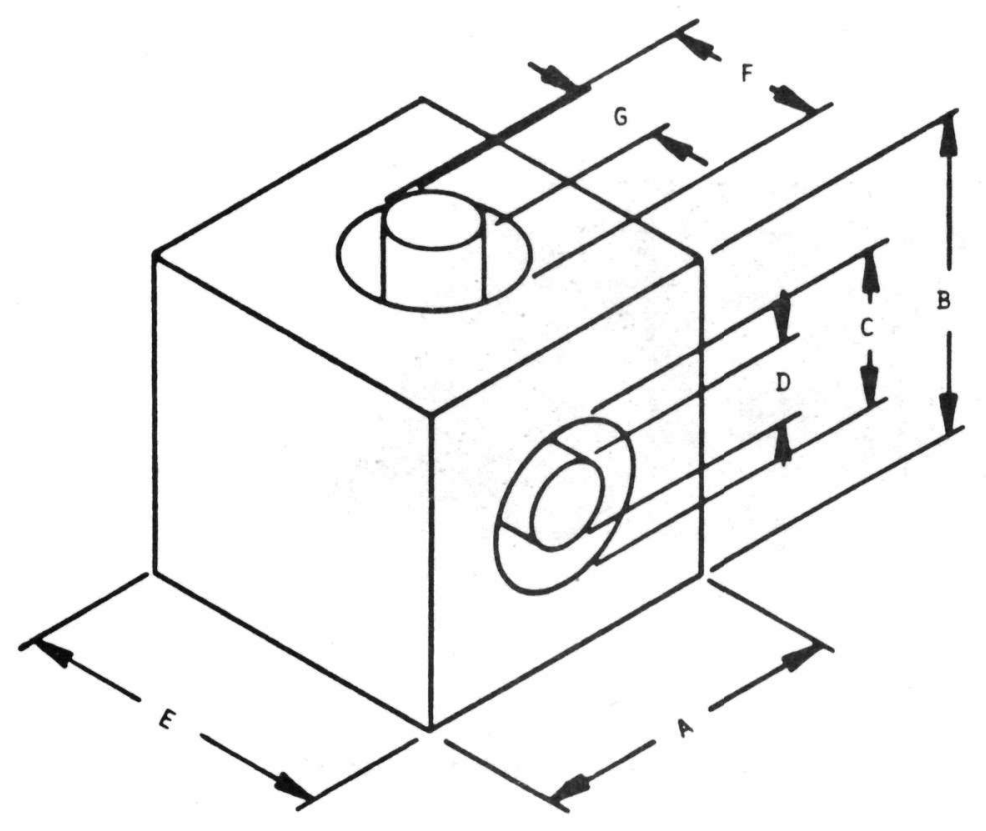

\begin{tabular}{|c|c|c|c|}
\multicolumn{1}{c}{$\begin{array}{c}\text { Poly- } \\
\text { Corbonate } \\
\text { Model } \\
\text { (MM) }\end{array}$} & $\begin{array}{c}\text { HLM } \\
\text { Graphite } \\
\text { Model } \\
\text { (MM) }\end{array}$ & $\begin{array}{c}\text { HLM } \\
\text { Graphite } \\
\text { Prototype } \\
\text { (MM) }\end{array}$ \\
\hline A & 50.8 & 50.8 & 175 \\
\hline B & 50.8 & 50.8 & 175 \\
\hline C & 25.4 & 25.4 & 88 \\
\hline D & 12.7 & 12.7 & 44 \\
\hline E & 50.8 & 50.8 & 175 \\
\hline F & 25.4 & 25.4 & 88 \\
\hline G & 12.7 & 12.7 & 44 \\
\hline
\end{tabular}

Fig. 7. Two-dimensional core-block dimensions.

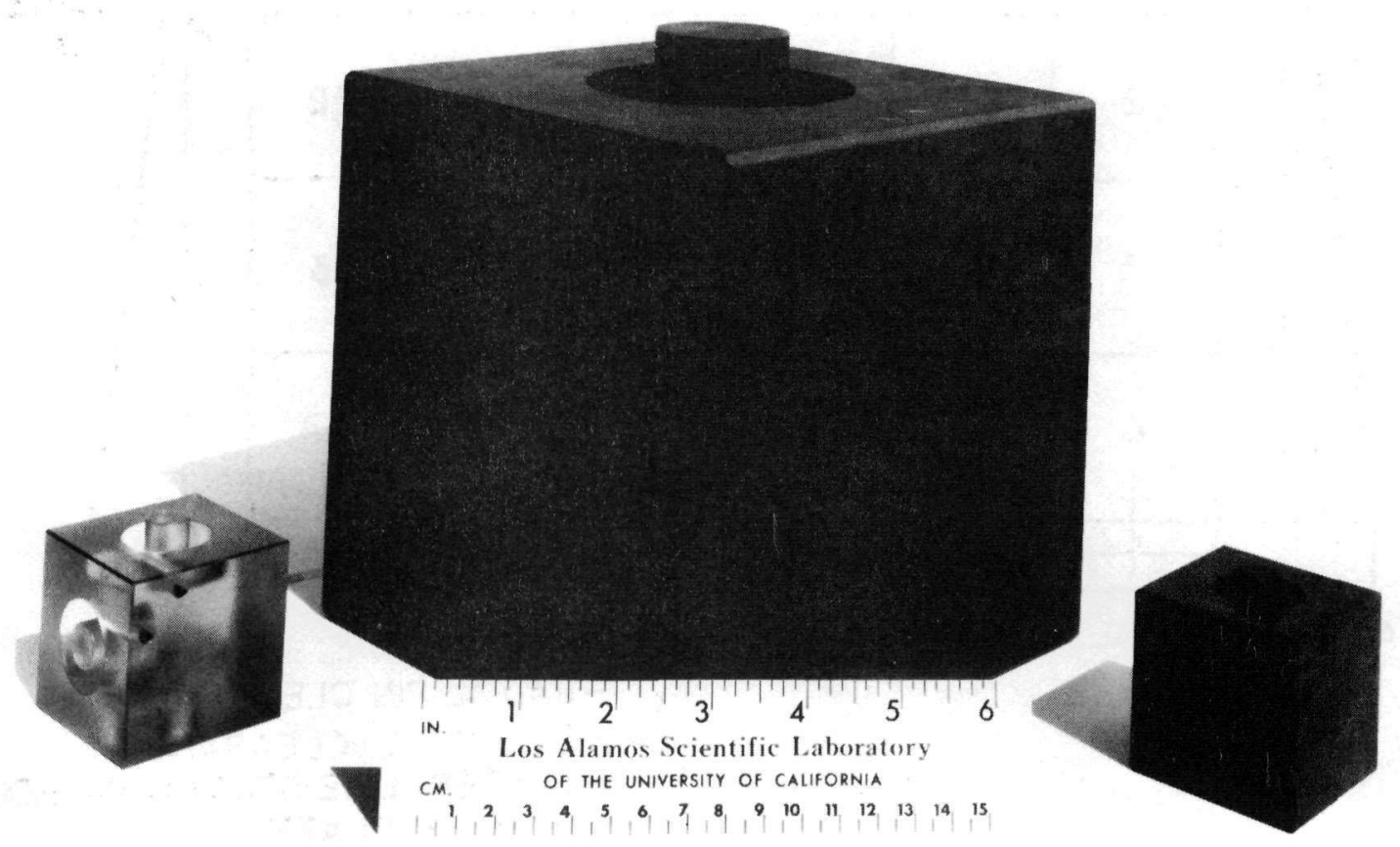

Fig. 8. Two-dimensional core blocks. 


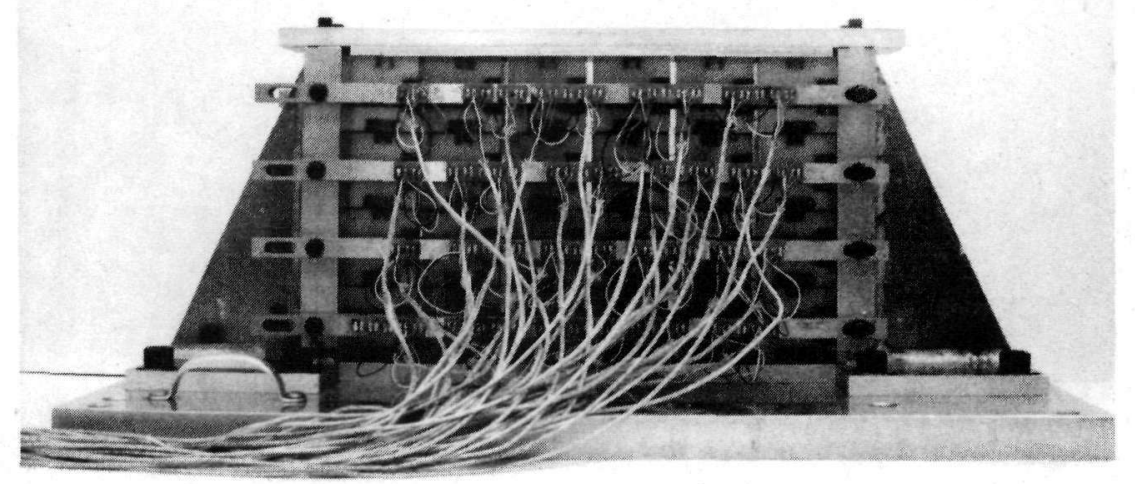

Fig. 9. Model mounted and ready for testing.

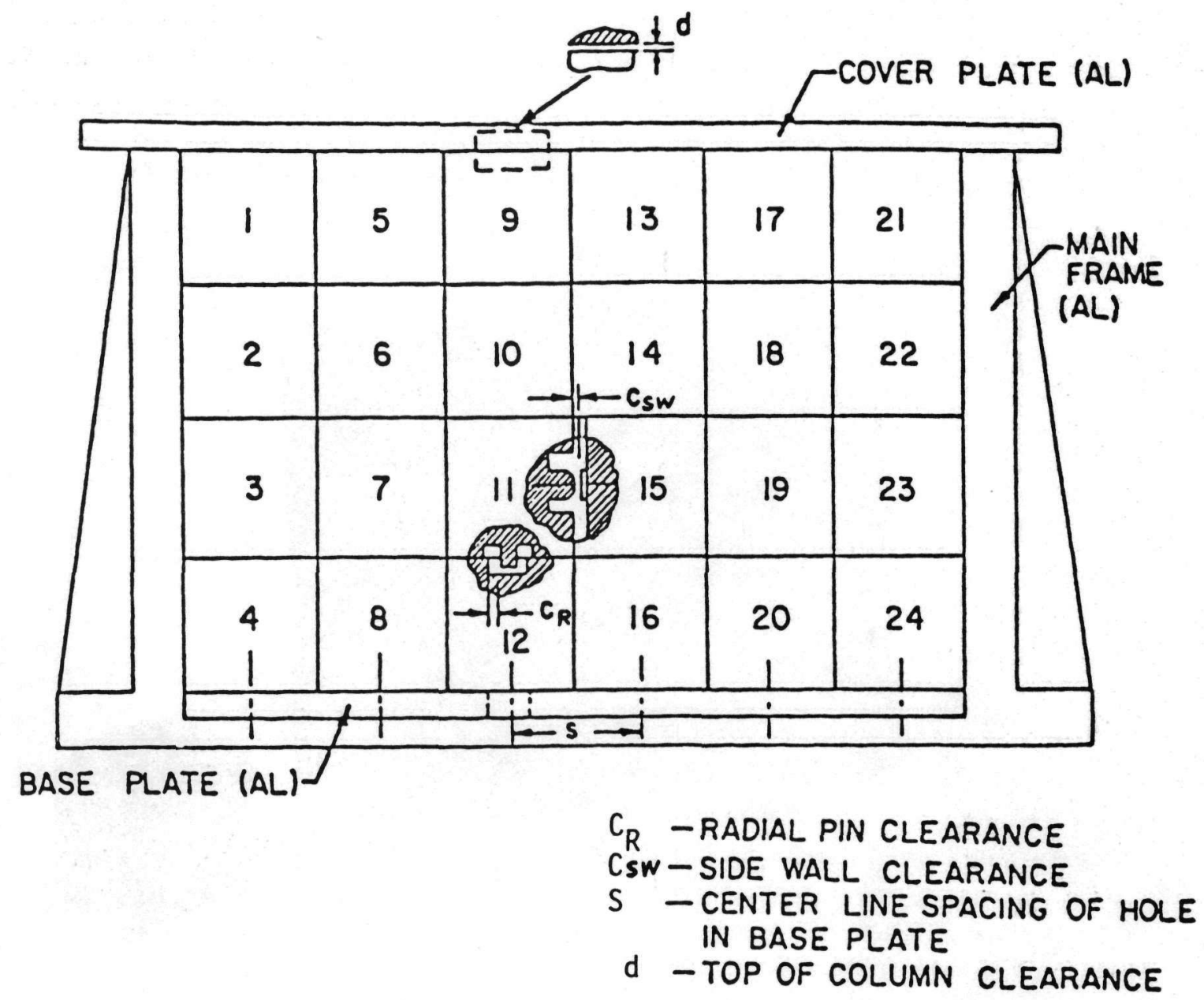

Fig. 10. Block clearance identification. 
Table IV, together with Fig. 10, shows the values of clearances actually set in each of the five series of tests. The Series 1 configuration represents a "tight" array; shear pin radial clearance $\left(C_{R}\right)$ and side wall clearance $\left(C_{\text {SW }}\right)$ are set at $0.075 \%$ and $0.5 \%$ of block width, respectively.

The Series 2 configuration represents an array with "loose" pins and small side wall clearance, shear pin radial clearance $\left(C_{R}\right)$ has been increased to $0.4 \%$ of block width while the side wall clearance $\left(C_{S W}\right)$ has been held at $0.5 \%$ of block width. Series 3,4 , and 5 configurations involve a constant $C_{R}$ with increasing $\mathrm{C}_{S W}$; to 1,2 , and $3 \%$ of block width, respectively. The radial pin clearance was varied by reboring the pin socket in each block following the Series 1 tests. The side wall clearance was varied by removing the blocks from the test mounting frame after each test series, and reassembling on a base plate having a different centerline spacing (S), and repositioning the end plates to accommodate the new total width.

Two tests were conducted on each of the five model configurations: (1) a \pm l-g (zero-pk)5-Hz sinusoidal base excitation, and (2) a 1-g (zero-pk) simulated earthquake that had been properly frequency scaled. The data obtained from these tests are summarized in Tables $V$ and $V I$.

TABLE IV

CLEARANCE VALUES ${ }^{a}$

Test Series

1
2
3
4
5

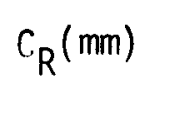

$0.038^{b}$

$0.203^{\mathrm{C}}$

$0.203^{\mathrm{C}}$

$0.203^{\mathrm{C}}$

$0.203^{\mathrm{C}}$
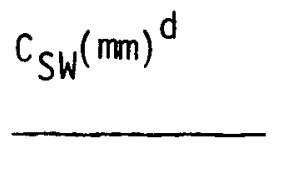

0.254

0.254

0.508

1.016

1.524
$\mathrm{S}(\mathrm{mm})$

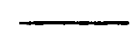

53.721

53.721

53.975

54.483

54.991 $d(m m)$

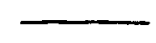

0.254

0.254

0.254

0.254

0.254

a. Refer to Fig. 10.

b. Pin diam $=12.700 \mathrm{~mm}$

Socket diam (in blocks and base plate) - $12.776 \mathrm{~mm}$.

c. Pin diam $=12.700 \mathrm{~mm}$

Socket diam in blocks $=13.106 \mathrm{~mm}$

Socket diam in base plate $=13.208 \mathrm{~mm}$.

d. Nominal block width (incl. two impact pieces) $=53.467$. 
TABLE $V$

SHEAR PIN PEAK FORCES (Newtons)

$1 \mathrm{~g}$, Earthquake

Test Series Number

Level $1 \frac{1}{17.2} \quad \frac{2}{20.0} \quad \frac{3}{21.8} \quad \frac{4}{28.0} \quad \frac{5}{29.4}$

Level $2 \quad 11.6$

$\begin{array}{lll}10.2 & 12.0 & 11.6\end{array}$

9.8

13.3

18.7

16.

31.3

32.4
$1 \mathrm{~g}$, Sinusoidal $(5 \mathrm{~Hz})$

Test Series Number

$\begin{array}{ccccc}\frac{1}{13.2} & \frac{2}{20.0} & \frac{3}{24.9} & \frac{4}{34.7} & \frac{5}{32.0} \\ 14.6 & 12.0 & 16.5 & 14.7 & 29.4 \\ 29.9 & 10.2 & 13.3 & 30.0 & 23.1 \\ 38.6 & 22.7 & 21.8 & 40.5 & 43.1 \\ 38.6 & 22.7 & 24.9 & 40.5 & 43.1\end{array}$

TABLE VI

SIDE WALL CONTACT PEAK FORCES (Newtons)

$1 \mathrm{~g}$, Earthquake

Test Series Number

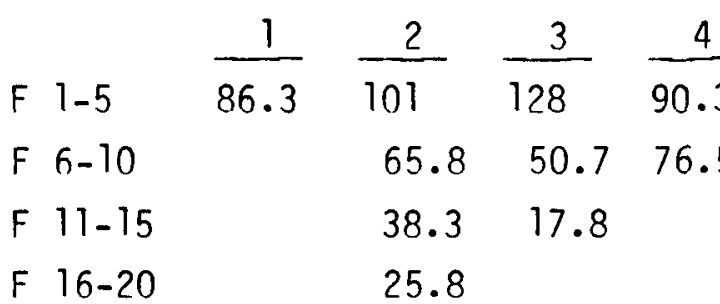

$1 \mathrm{~g}$, Sinusoidal $(5 \mathrm{~Hz})$

Test Series Number

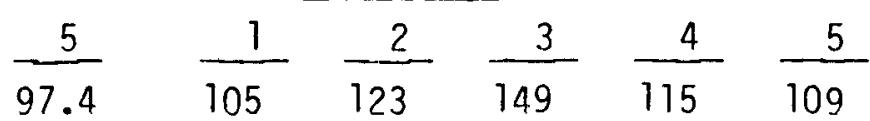

$\begin{array}{llll}26.7 & 77.4 & 75.6 & 76.5\end{array}$

$44.5 \quad 22.2$

25.8

$\operatorname{Max}$

$\begin{array}{lll}86.3 & 101 & 128\end{array}$

$90.3 \quad 97.4$

105

$123 \quad 149 \quad 115$

109

It is obvious that both the size of either clearance $\left(C_{R}\right.$ or $\left.C_{S W}\right)$ and the relative size of the two clearances have considerable effect on both the magnitude and distribution of the forces developed in response to base motion excitation. From the data presented we can make the following observations:

1. Comparing Test Series No. 2 with Test Series No. 1. Increasing the radial shear pin clearance while the side wall clearance is held constant reduces the shear pin forces. The maximum shear pin force is reduced by $38 \%$.*

*In this and the following comparisons, the data obtained during the simulated seismic tests are used as a basis for computations. 
Simultaneously, the maximum side wall force is increased by $17 \%$, and the blocks at all levels experience contact in the latter case.

2. Comparing Test Series Nos. 3, 4, and 5 with Test Series No. 2. Increasing the side wall clearance while holding the radial shear pin clearance constant increases the shear pin forces. For example, an increase in the side wall clearance from 0.5 to $2 \%$ of block width (Test Series No. 2 with Test Series No. 4) results in an increase in shear pin force of $80 \%$. The data show a slight reduction of shear pin force as the side wall clearance is increased from 2 to $3 \%$ of block width; however, it is clear that beyond a certain value of the ratio $C_{S W} / C_{R}$, there will be no side wall contact and the shear pin forces will be independent of further increases in $C_{S W}$. Increasing the side wall clearance while holding the radial shear pin clearance constant may either increase or decrease side wall contact forces, but, in general, the side wall contact forces are less sensitive to changes in either kind of clearance $\left(C_{S W}\right.$ or $C_{R}$ ) than are the shear $p$ in forces. The most noticeable effect of increasing side wall clearance while holding radial shear pin clearance constant is the progressive elimination of side wall forces on the blocks at the lower levels.

3. Although sinusoidal base excitation at the proper amplitude and frequency can be made to produce almost the same magnitude of contact forces as are produced by seismic excitation, it is incorrect to conclude that sinusoidal excitation can be used to replace seismic excitation. Even when the duration of the sinusoidal excitation is limited to the duration of the active portion of the seismic signal, many more impacts are produced by the sinusoidal test. For example, during the Series 3 tests, the maximum shear pin force is developed at $\mathrm{S}_{9}$ (see Fig. 6). During seismic excitation only 10 shear pin impacts occur and the average force of these impacts is only 9.83 Newtons (which is $45 \%$ of the maximum value). However, during a period of sinusoidal excitation equal to the duration of the seismic pulse (approximately $3 \mathrm{~s}$ ) the same shear pin receives 45 impacts. Further, the average force of these 45 impacts is 19.2 Newtons (which is $77 \%$ of the maximum value). During the Series 3 tests, the maximum side wall contact force is developed at $F_{4^{*}}$. During seismic excitation only 29 side wall impacts occur, and the average force of these impacts is only 45 Newtons (which is $35 \%$ of the maximum value). However, during a $3-5$ period of sinusoidal excitation, there are 150 impacts with an average 
value of 66.5 Newtons, which is $45 \%$ of the maximum value. Because graphite is subject to low-cycle fatigue failure, the number and amplitude of impacts produced during a test program is important.

This limited study of the effect of clearances in a block-type core indicates that the magnitude of these clearances is very important in determining the response of the core to a seismic event. Uncertainty concerning the magnitude of these clearances will limit the value of any predictions made (using either analysis or experiment) concerning forces developed. Changes in these clearances that may occur during core life must be accounted for.

\section{CLOSURE}

The model studies reported here do not represent any existing or proposed gas-cooled reactor hence, the actual values of forces measured are of no special interest. However, we believe that this scale model study clearly demonstrates the following points.

1. Scale models of block-type reactor cores can be constructed that give valid predictions of prototype behavior during seismic excitation.

2. Scale models can be made sufficiently small so that they can be tested under simulated seismic conditions using state-of-the-art test equipment.

3. Although sinusoid excitation tests may provide useful preliminary or supplemental information, it is very doubtful that sinusoidal testing alone will suffice to allow the accurate prediction of prototype behavior under seismic conditions. Indeed, sinusoidal testing of models, or prototype components, should be undertaken with great care because such testing may constitute severe overtesting.

4. Scale models can be designed and tested in such a way that parameter studies are possible. As a result, scale models may be useful during preliminary design studies as well as for the evaluation of a final design. 


\section{REFERENCES}

1. A. J. Neylan and W. Gorholt, "Design Development of the HTGR Core and Its Support Structure--Seismic Considerations," Nuc. Eng. and Des., 29, 231-242, (1974).

2. R. C. Dove, "Scaling Laws for HTGR Core Block Seismic Response," Proc. Japan-U.S. Seminar on HTGR Safety Technology, in Seismic Research, (Brookhaven National Laboratory report BLN-NUREG-50689, September 1977), Vol. 1, pp. 75-87.

3. J. G. Bennett, R. C. Dove, and J. L. Merson, "Seismic Response of a Block-Type Reactor Core," Am. Soc. Civ. Eng. Publication 77-DET-138, presented at the ASME Design Engineering Technical Conference, Chicago, Illinois, September 1977, New York.

4. W. L. Kirk, "HTGR Safety Research Program, January-March 1975," Los Alamos National Laboratory report LA-5975-PR (June 1975).

5. W. L. Kirk, "HTGR Safety Research Program, April-June 1975," Los Alamos National Laboratory report LA-6054-PR (September 1975).

6. "Nuclear Reactor Safety - Quarterly Progress Report, January 1-March 31, 1979," pp. 122-130, Los Alamos National Laboratory report LA-7867-PR NUREG/CR-0868 (June 1979). 
Nuclear Regulatory Commission, R8, Bethesda, Maryland Technical Information Center, Oak Ridge, Tennessee

Los Alamos National Laboratory, Los Alamos, New Mexico
Copies 298

50

350 